\title{
(士)-Evodiakine, A Pair of Rearranged Rutaecarpine-Type Alkaloids From Evodia rutaecarpa
}

\author{
Yan-Hong Li $\cdot$ Yu Zhang $\cdot$ Li-Yan Peng • \\ Xiao-Nian Li $\cdot$ Qin-Shi Zhao $\cdot$ Rong-Tao Li $\cdot$ \\ Xing-De Wu
}

Received: 3 November 2016/Accepted: 3 November 2016/Published online: 21 November 2016

(C) The Author(s) 2016. This article is published with open access at Springerlink.com

\begin{abstract}
Evodiakine (1a and 1b), a pair of rearranged rutaecarpine-type alkaloids with an unprecedented 6/5/5/7/6 ring system, were isolated from the nearly ripe fruits of Evodia rutaecarpa. Separation of the enantiomers have been achieved by chiral HPLC column. The structures of $( \pm$ )-evodiakine were unambiguously elucidated by 1D and 2D NMR spectra, mass spectrometry, and single-crystal X-ray diffraction. Their absolute configurations were determined by comparison of experimental and calculated electronic circular dichroism spectra. A hypothetical biogenetic pathway for $( \pm)$ evodiakine was also proposed. Compounds $\mathbf{1 a}, \mathbf{1 b}$, and the racemate (1) were tested for their cytotoxic and anti-inflammatory activities.
\end{abstract}

Graphical Abstract

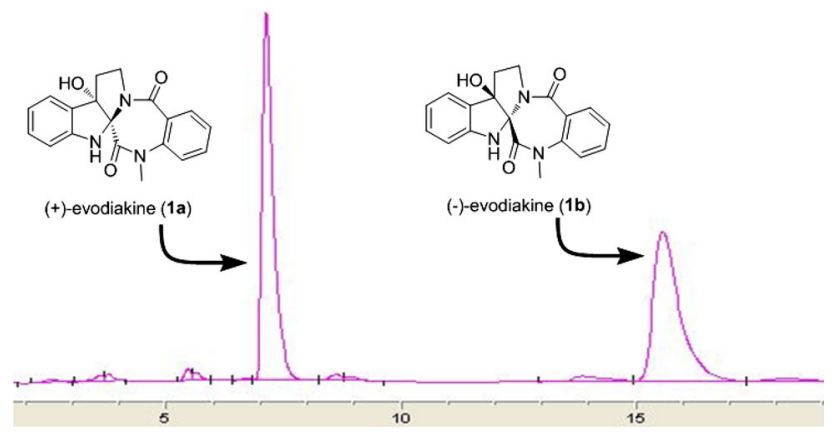

Keywords Evodia rutaecarpa $\cdot( \pm)$-Evodiakine $\cdot$ Rutaecarpine-type alkaloids

Electronic supplementary material The online version of this article (doi:10.1007/s13659-016-0113-7) contains supplementary material, which is available to authorized users.

Y.-H. Li · Y. Zhang · L.-Y. Peng · X.-N. Li · Q.-S. Zhao ·

X.-D. Wu $(\bowtie)$

State Key Laboratory of Phytochemistry and Plant Resources in West China, Kunming Institute of Botany, Chinese Academy of Sciences, Kunming 650201, People's Republic of China e-mail: wuxingde@mail.kib.ac.cn
Y.-H. Li

Key Laboratory of Chemistry in Ethnic Medicinal Resources, State Ethnic Affairs Commission \& Ministry of Education, School of Ethnic Medicine, Yunnan Minzu University, Jingming South Road, Chenggong New District, Kunming 650504, Yunnan, People's Republic of China 


\section{Introduction}

Evodia rutaecarpa (Juss.) Benth., a small tree belonging to the family Rutaceae mainly, is distributed in the south regions of Qinling in China [1]. The dried and nearly ripe fruits (Evodiae Fructus), called Wu-Zhu-Yu in Chinese (Goshuyu in Japanese), are used in traditional Chinese medicine for the treatment of various diseases, especially for treating headache, abdominal pain, migraines, chill limbs, postpartum hemorrhage, dysmenorrheal, diarrhea, nausea and hypertension [2]. Previous phytochemical study on E. rutaecarpa have focused on rutaecarpine-type alkaloids that produce a number of characteristic compounds with different ring system, including rutaecarpine $(6 / 5 / 6 / 6 /$ 6) [3], evodiagnine (6/5/6/7/6) [4], and wuzhuyurutine A $(6 / 5 / 5 / 6 / 6)$ [5], as well as several seco-derivatives, such as goshuyuamide I [6] and wuchuyuamide I [7] (Fig. 1). Our previous study on this plant reported three new alkaloids, evollionines $\mathrm{A}-\mathrm{C}$, together with evollionines $\mathrm{A}$ and $\mathrm{B}$ belonging to seco-ring rutaecarpine-type alkaloids [8]. A continuous study on the plant led to the isolation of a pair of rearranged rutaecarpine-type derivatives, (+)-evodiakine (1a) and (-)-evodiakine (1b), containing the interesting 6/5/5/7/6 ring system depicted as in Fig. 2. Their structure elucidation was unambiguously achieved by spectroscopic data, single-crystal X-ray diffraction, and electronic circular dichroism (ECD).

\section{Results and Discussion}

Evodiakine (1) was obtained as colorless needles. Its molecular formula $\mathrm{C}_{19} \mathrm{H}_{17} \mathrm{~N}_{3} \mathrm{O}_{3}$ was deduced from the HREI-MS at $\mathrm{m} / 2335.1284\left([\mathrm{M}]^{+}\right.$, calc. 335.1270), corresponding to 13 degrees of unsaturation. The characteristic absorption at 3409 (OH and/or $\mathrm{NH}), 1602$ and $1467 \mathrm{~cm}^{-1}$ (aromatic ring) in IR spectrum, and at 203, 218, $288 \mathrm{~nm}$ in $\mathrm{UV}$ spectrum, together with a $\mathrm{OH}$ signal $\left(\delta_{\mathrm{H}} 6.49, \mathrm{~s}\right)$ and a $\mathrm{NH}\left(\delta_{\mathrm{H}} 6.00, \mathrm{~s}\right)$ signal in the ${ }^{1} \mathrm{H}$ NMR spectrum (Table 1) implied the possibility of a dihydroindoline derivative for $\mathbf{1}$ [7]. In addition, the proton signals at $\delta_{\mathrm{H}} 6.56(\mathrm{~d}$, $J=7.7 \mathrm{~Hz}), 7.08(\mathrm{t}, J=7.7 \mathrm{~Hz}), 6.81(\mathrm{t}, J=7.7 \mathrm{~Hz})$, $7.33(\mathrm{~d}, J=7.7 \mathrm{~Hz})$; and $\delta_{\mathrm{H}} 7.58(\mathrm{~d}, J=8.0 \mathrm{~Hz}), 7.74(\mathrm{t}$, $J=8.0 \mathrm{~Hz}), 7.43(\mathrm{t}, J=8.0 \mathrm{~Hz}), 7.72(\mathrm{~d}, J=8.0 \mathrm{~Hz})$ displayed characteristic of two ortho-disubstituted benzenoid rings. The ${ }^{13} \mathrm{C}$ NMR, DEPT, and HSQC spectra suggested that $\mathbf{1}$ exhibited seven other carbon signals due

Y.-H. Li · R.-T. Li (ه)

Faculty of Life Science and Technology, Kunming University of Science and Technology, Kunming 650050, People's Republic of China

e-mail: 1rt512@163.com

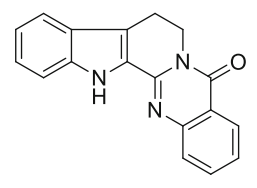

rutaecarpine

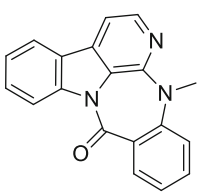

evodiagnine

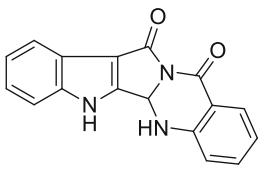

wuzhuyurutine $\mathrm{A}$

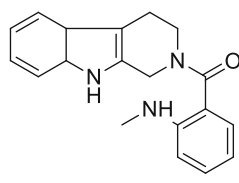

goshuyuamide I

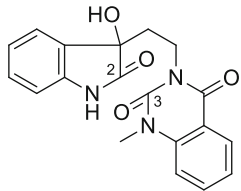

wuchuyuamide I
Fig. 1 The known characteristic compounds from E. rutaecarpa

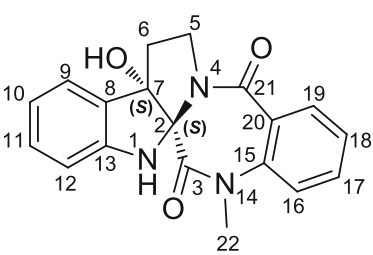

1 a

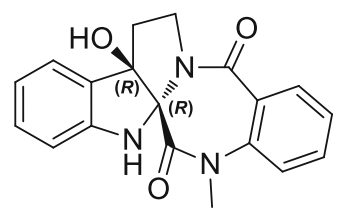

$1 \mathrm{~b}$
Fig. 2 Structures of (+)-evodiakine (1a) and (-)-evodiakine (1b)

Table 1 NMR data for compound 1 in DMSO- $d_{6}$. $\left(600 \mathrm{MHz}\right.$ for ${ }^{1} \mathrm{H}$ and $150 \mathrm{MHz}$ for ${ }^{13} \mathrm{C}$ )

\begin{tabular}{|c|c|c|c|}
\hline Position & $\delta_{\mathrm{H}}$, mult. $(J$ in $\mathrm{Hz})$ & $\delta_{\mathrm{C}}$, mult. & HMBC $\left({ }^{1} \mathrm{H}-{ }^{13} \mathrm{C}\right)$ \\
\hline 2 & & $91.2, \mathrm{C}$ & \\
\hline 3 & & 168.6, C & \\
\hline 5 & $\begin{array}{l}3.87, \mathrm{~m} \\
3.10, \mathrm{~m}\end{array}$ & $45.8, \mathrm{CH}_{2}$ & $2,6,7$ \\
\hline 6 & $\begin{array}{l}2.65, \mathrm{~m} \\
2.35, \mathrm{~m}\end{array}$ & $33.1, \mathrm{CH}_{2}$ & $2,5,7,8$ \\
\hline 7 & & 79.0, C & \\
\hline 8 & & $130.1, \mathrm{C}$ & \\
\hline 9 & $6.56, \mathrm{~d}(7.7)$ & $111.9, \mathrm{CH}$ & 8,11 \\
\hline 10 & $7.08, \mathrm{t}(7.7)$ & $129.8, \mathrm{CH}$ & 12,13 \\
\hline 11 & $6.81, \mathrm{t}(7.7)$ & $119.9, \mathrm{CH}$ & 9,10 \\
\hline 12 & $7.33, \mathrm{~d}(7.7)$ & $123.2, \mathrm{CH}$ & $2,10,13$ \\
\hline 13 & & 148.2, C & \\
\hline 15 & & $138.3, \mathrm{C}$ & \\
\hline 16 & $7.58, \mathrm{~d}(8.0)$ & $123.3, \mathrm{CH}$ & $15,17,20,21$ \\
\hline 17 & $7.74, \mathrm{t}(8.0)$ & $132.9, \mathrm{CH}$ & $15,16,19$ \\
\hline 18 & $7.43, \mathrm{t}(8.0)$ & $126.2, \mathrm{CH}$ & $15,16,20$ \\
\hline 19 & $7.72, \mathrm{~d}(8.0)$ & $130.2, \mathrm{CH}$ & $15,17,21$ \\
\hline 20 & & $127.9, \mathrm{C}$ & \\
\hline 21 & & 164.3, C & \\
\hline $\mathrm{N}-\mathrm{Me}$ & $3.43, \mathrm{~s}$ & $36.4, \mathrm{CH}_{3}$ & 3,15 \\
\hline $\mathrm{N}-\mathrm{H}$ & $6.00, \mathrm{~s}$ & & $2,3,7,8,13$ \\
\hline 7-OH & $6.49, \mathrm{~s}$ & & $2,7,8$ \\
\hline
\end{tabular}




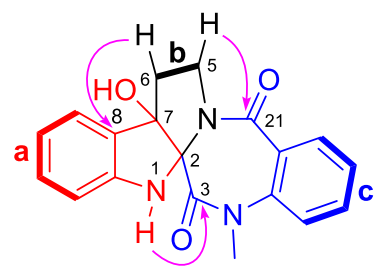

evodiakine (1)

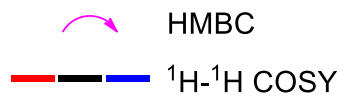

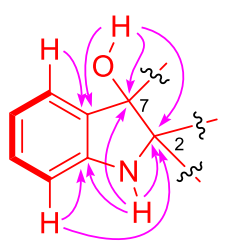

(i)

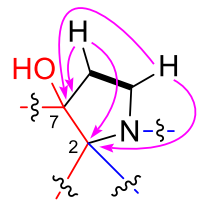

(ii)

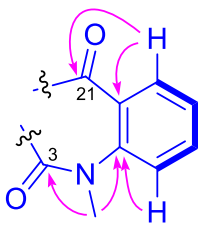

(iii)
Fig. 3 Key HMBC and COSY correlations of evodiakine (1)

to two aliphatic methylenes, four quaternary carbons (two amide groups at $\delta_{\mathrm{C}} 164.3$ and 168.6, one $\mathrm{OH}$-substituted quaternary carbon at $\delta_{\mathrm{C}} 79.0$, and one carbinolamine quaternary carbon at $\left.\delta_{\mathrm{C}} 91.2\right)$, and one $N$-methyl $\left(\delta_{\mathrm{H}} 3.43 ; \delta_{\mathrm{C}}\right.$ 36.4). These spectroscopic data suggested that $\mathbf{1}$ was an alkaloid with polyheterocyclic systems.

The structure of $\mathbf{1}$ was established by the further 2D NMR data analysis. In the ${ }^{1} \mathrm{H}-{ }^{1} \mathrm{H}$ COSY spectrum (Fig. 3), the cross peaks of $\mathrm{H}-9 / \mathrm{H}-10 / \mathrm{H}-11 / \mathrm{H}-12$ and $\mathrm{H}-16 / \mathrm{H}-17 / \mathrm{H}-$ 18/H-19 confirmed the presence of the two H-bearing structural fragments (a and c) and consistent with the ${ }^{1} \mathrm{H}$ NMR spectrum. Additionally, the ${ }^{1} \mathrm{H}^{-1} \mathrm{H}$ COSY correlations of $\mathrm{H}_{2}-5 / \mathrm{H}_{2}-6$ suggested the existence of a $\mathrm{CH}_{2} \mathrm{CH}_{2}$ alkyl fragment (b). The fragment of a together with the HMBC correlations from OH-7 $\left(\delta_{\mathrm{H}} 6.49\right)$ to C-2, C-7, and C-8, from $\mathrm{N}_{1}-\mathrm{H}\left(\delta_{\mathrm{H}} 6.00\right)$ to C-2, C-7, C-8, and C-13, from $\mathrm{H}-9$ with $\mathrm{C}-8$ and $\mathrm{C}-11$, and from $\mathrm{H}-12$ to $\mathrm{C}-2, \mathrm{C}-10$, and $\mathrm{C}-13$ revealed the presence of a 2,3-disubstituted indolin-3ol moiety (i) in 1. The HMBC correlations of $\mathrm{H}_{2}-5$ with C-2, C-6, and C-7 and of $\mathrm{H}_{2}-6$ with C-2, C-5, C-7, and C-8 demonstrated that the indolin-3-ol moiety (i) was fused with a pyrrolidine ring (ii) via $\mathrm{C}-2$ and $\mathrm{C}-7$. In addition, the rest structural fragment (iii) was established by the HMBC correlations of H-16 with C-15, C-17, C-20, and C-21, of H-19 with C-15, C-17, and C-21, and of $\mathrm{H}_{3}-22$ with C-3 and C-15. Furthermore, the HMBC correlation of $\mathrm{N}_{1}-\mathrm{H}$ with $\mathrm{C}-3$, as well as the downfield chemical shift of $\mathrm{C}-2$ at $\delta_{\mathrm{C}}$ 91.2, suggested that the carbonyl group (C-3) was connected to the C-2 of the indolin-3-ol moiety (i). Finally, the absence of an N-4 proton resonance in the ${ }^{1} \mathrm{H}$ NMR spectrum combined with the molecular composition suggested that C-21 was linked to N-4 of the pyrrolidine moiety (ii). Thus, the structure of $\mathbf{1}$ was identified as a pentacyclic alkaloid by fusing indole and the secopyrroloquinazolone rings [9] (Fig. 3). This deduction was

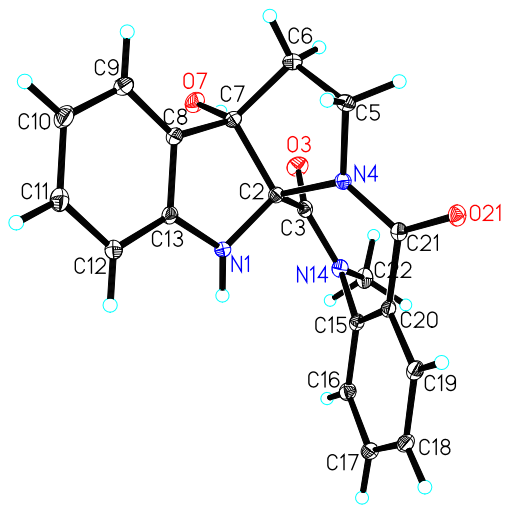

Fig. 4 X-ray crystal structure of evodiakine (1)

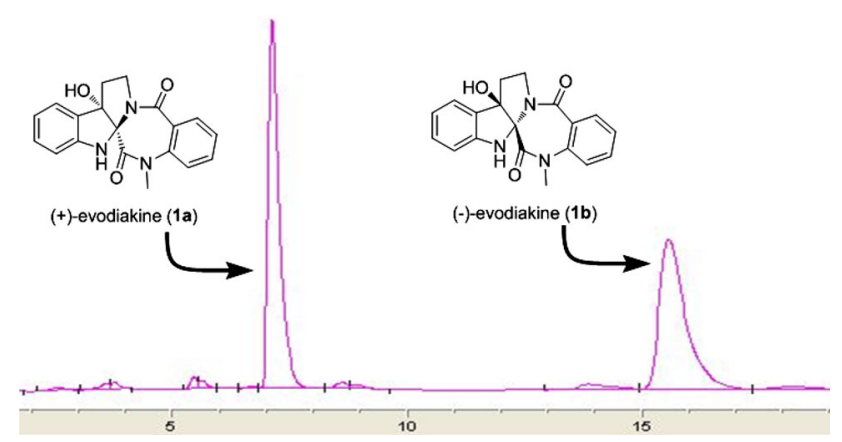

Fig. 5 The HPLC profiles of separation of (+)- and (-)-evodiakine on chiral IC column

further confirmed by an X-ray diffraction experiment using Mo $\mathrm{K} \alpha$ radiation (Fig. 4).

Evodiakine $(\mathbf{1})$ was optically inactive, $[\alpha]_{\mathrm{D}}^{24.8} \approx 0$ (c $0.12, \mathrm{MeOH})$, indicating that it was obtained as a racemate. Subsequent HPLC separation of $\mathbf{1}$ on a chiral column prior to HPLC separation yielded two compounds, $\mathbf{1 a}$ and $\mathbf{1 b}$ (Fig. 5). However, the isolated compounds showed opposite optical rotation, and their ECD spectra displayed mirror curves as shown in Fig. 6. This confirmed the successful separation of enantiomers, $(+)$-evodiakine (1a) and $(-)$-evodiakine (1b). To secure unambiguous confirmation of the absolute configuration of compounds $\mathbf{1 a}$ and $\mathbf{1 b}$, the

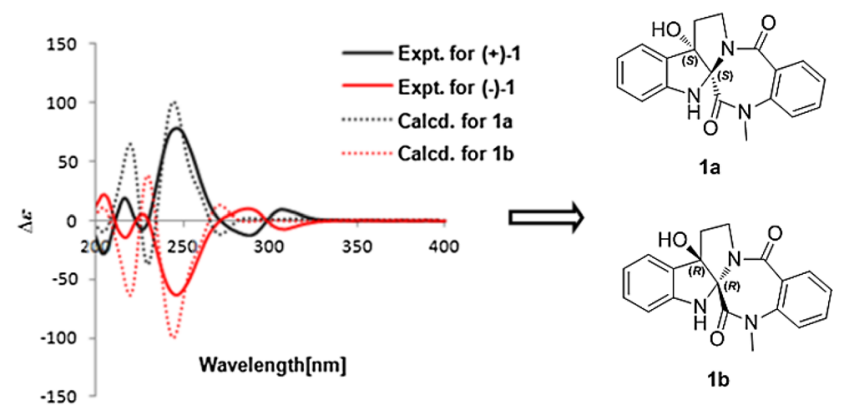

Fig. 6 Experimental and calculated ECD spectra of compounds 1a and $\mathbf{1 b}$ 
ECD calculation at the B3LYP/6-31G** level in Gaussian 03 program package was carried out, which provided vindication of their configuration [10]. In the 200-400 nm region, the calculated ECD spectra of compounds 1a and 1b were consistent with the experimental ECD spectra of $(+)-\mathbf{1}$ and (-)-1, respectively. Thus, the absolute configuration of compound 1a was determined to be $2 S, 7 S$-evodiakine, as well as that of $\mathbf{1 b}$ was revealed as $2 R, 7 R$ evodiakine.

By comparison with known rutaecarpine-type alkaloids, compound $( \pm)-\mathbf{1}$ was regarded as a rearranged rutaecarpine-type alkaloid with an unprecedented 6/5/5/7/6 ring system. From a biogenetic point of view, $( \pm)$-evodialine (1) would plausibly be derived from a common rutaecarpine-type alkaloid, evodianinine (2), via the sequence shown in Scheme 1. Compound 2 underwent isomerization and oxidation to produce intermediate $\mathbf{B}$ [11]. Then, the $\mathrm{C}-3 / \mathrm{N}-4$ bond cleavage and the formation of a heptatomic ring accomplished via the key intermediate $\mathbf{C}$ [12]. The rings $\mathrm{C}$ and $\mathrm{D}$ rearrangement of $\mathbf{B}$ via attack of the $\mathrm{NH}$ in $\mathbf{C}$ onto the imine carbon yielded the structure $\mathbf{D}$, which was followed by reduction of the C-5/C-6 double bond to produce compounds $\mathbf{1 a}$ and $\mathbf{1 b}[13,14]$.

Compounds $\mathbf{1 a}, \mathbf{1 b}$, and the racemate (1) were evaluated for their anti-inflammatory and cytotoxic activities, but none of them showed ability to inhibit NO production of LPS-stimulated RAW 264.7 macrophages, as well as cytotoxicity against HL-60, SMMC-7721, A-549, MCF-7, and SW-480 cancer cell lines with $\mathrm{IC}_{50}$ values of more than $40 \mu \mathrm{M}$.

\section{Experimental Section}

\subsection{General}

Melting points were obtained on an X-4 micro melting point apparatus. Optical rotations were measured with a
Perkin-Elmer model 241 polarimeter. UV spectra were recorded using a Shimadzu UV-2401A spectrophotometer. IR spectra were determined on a Tensor-27 infrared spectrophotometer with $\mathrm{KBr}$ pellets. ECD spectra were obtained on a JASCO J-810 spectrophotometer. 1D and 2D NMR spectra were performed on Avance III-600 spectrometers with TMS as an internal standard. ESIMS and HREIMS were measured using an API-QSTAR-Pulsar-1 or VG Auto Spec-3000 instruments. X-ray diffraction was conducted using Bruker APEX DUO diffractometer with graphite-monochromated MoK $\alpha$ radiation. MPLC was performed on a Lisui EZ Purify III System including pump manager $\mathrm{P} 03$, detector modules $\mathrm{P} 02$, and fraction collector P01 (Shanghai Lisui Chemical Engineering Co., Ltd., Shanghai, China). Column chromatography (CC) was performed over silica gel (200-300 mesh, Qingdao Marine Chemical Co. Ltd., Qingdao, China), MCI gel (CHP 20P, 75-150 $\mu \mathrm{m}$, Mitsubishi Chemical Corporation, Japan). Thin-layer chromatography (TLC) was carried out on silica gel $\mathrm{GF}_{254}$ on glass plates (Qingdao Marine Chemical Co. Ltd.) using various solvent systems and spots were visualized by spraying improved Dragendorff's reagent to the silica gel plates.

\subsection{Plant Materials}

The dried and nearly ripe fruits of E. rutaecarpa were purchased from the Kunming Ju-Hua village pharmaceutical sale market, Yunnan province, P. R. China.

\subsection{Extraction and Isolation}

The dried and near ripe fruits of E. rutaecarpa $(20.0 \mathrm{~kg})$ were extracted with $\mathrm{MeOH}(3 \times 10 \mathrm{~L})$ at room temperature for $24 \mathrm{~h}$ each time. The $\mathrm{MeOH}$ extracts were evaporated under reduced pressure to give a residue, which was dissolved in $1 \% \mathrm{HCl}$, acidified to $\mathrm{pH} 2$, and then partitioned with EtOAc $(3 \times 4 \mathrm{~L})$. The acidic solution was

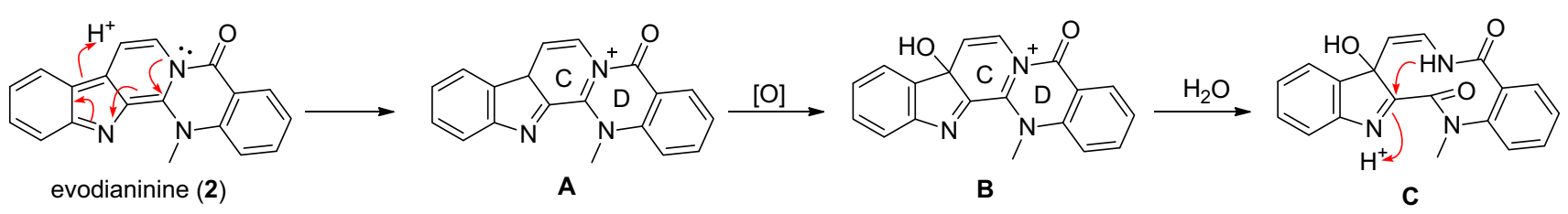<smiles>CN1CC2(Nc3ccccc3)CCCN2C(=O)c2ccccc21</smiles>

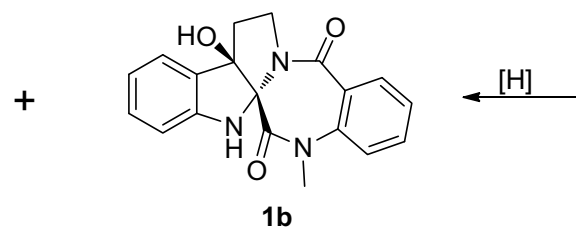<smiles>CN1C(=O)[C@@]2(C(O)c3ccccc3N1C)N1C=CC(=O)c3ccccc3C(=O)N12</smiles><smiles>C1#CCCC1</smiles>

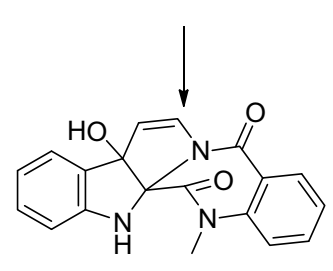

D

Scheme 1 Plausible biogenetic pathway of (+)-1a and (-)-1b 
basified using saturated $\mathrm{Na}_{2} \mathrm{CO}_{3}$ to $\mathrm{pH}$ 10, followed by exhaustive extraction with $\mathrm{CHCl}_{3}(3 \times 4 \mathrm{~L})$ to afford a extract $(36 \mathrm{~g})$. The $\mathrm{CHCl}_{3}$ extract was subjected to MPLC (MCI, $500.0 \mathrm{~g}, 25 \times 4 \mathrm{~cm}$ ) eluted with $\mathrm{MeOH} / \mathrm{H}_{2} \mathrm{O}$ $(40 \rightarrow 100 \%)$ to yield four fractions (Frs. I-IV). Fr. III $(10 \mathrm{~g})$ was applied to repeated $\mathrm{CC}\left(\mathrm{SiO}_{2}, 250.0 \mathrm{~g}\right.$, $50 \times 3 \mathrm{~cm}, \mathrm{CHCl}_{3}$ /acetone $9: 1 ; \mathrm{SiO}_{2}, 350.0 \mathrm{~g}, 60 \times 5 \mathrm{~cm}$, $\mathrm{CH}_{3} \mathrm{Cl} / \mathrm{MeOH} / \mathrm{Et}_{2} \mathrm{NH}$ 49:1:0.3) to provide compound $\mathbf{1}$ (13.0 mg).

\subsubsection{Evodiakine (1)}

Colorless needles (cyclohexane/acetone, 2:1); mp $218 \sim 220{ }^{\circ} \mathrm{C} ;[\alpha]_{\mathrm{D}}^{24.8} \approx 0(\mathrm{c} 0.12, \mathrm{MeOH}) ; \mathrm{UV}(\mathrm{MeOH})$ $\lambda_{\max }(\log \varepsilon): 288$ (3.43), 218 (4.35), 203 (4.38) nm; IR (KBr) $v_{\max }: 3409,2923,1637,1602,1467 \mathrm{~cm}^{-1} ;{ }^{1} \mathrm{H}$ and ${ }^{13} \mathrm{C}$ NMR data, see Table 1; ESIMS $m / z 358[\mathrm{M}+\mathrm{Na}]^{+}$; HREIMS $m / z \quad 335.1284\left([\mathrm{M}]^{+}\right.$, calcd for $\mathrm{C}_{19} \mathrm{H}_{17} \mathrm{~N}_{3} \mathrm{O}_{3}$ : 335.1270). (+)-evodiakine (1a): $[\alpha]_{\mathrm{D}}^{25.3}+421.1$ (c 0.15 , $\mathrm{MeOH}) ; \mathrm{ECD}(\mathrm{MeOH}) \lambda_{\max }(\Delta \varepsilon): 204(-19.45), 216$ $(+12.97), 227$ (-5.12), $246(+53.85), 287$ (-8.65), 306 $(+6.38) \mathrm{nm}$; (-)-evodiakine $(\mathbf{1 b}):[\alpha]_{\mathrm{D}}^{25.3}-422.7$ (c 0.20 , $\mathrm{MeOH}) ; \mathrm{ECD}(\mathrm{MeOH}) \lambda_{\max }(\Delta \varepsilon): 205(+14.61), 217$ $(-9.81), 227(+3.61), 246(-42.96), 287(+6.60), 308$ $(-5.02) \mathrm{nm}$.

\subsubsection{Crystal Data for Evodiakine (1)}

$\mathrm{C}_{19} \mathrm{H}_{17} \mathrm{~N}_{3} \mathrm{O}_{3} \cdot \mathrm{C}_{6} \mathrm{H}_{12}, M=419.51$, monoclinic, $a=19.629(2) \AA$, $b=10.1354(13) \AA, c=10.7440(13) \AA, \alpha=90.00^{\circ}, \beta=$ 98.410(2) ${ }^{\circ}, \gamma=90.00^{\circ}, V=2114.5(5) \AA^{3}, T=100(2) \mathrm{K}$, space group $P 21 / c, \quad Z=4, \mu(\operatorname{MoK} \alpha)=0.087 \mathrm{~mm}^{-1}$, 21663 reflections measured, 5933 independent reflections $\left(R_{\text {int }}=0.0312\right)$. The final $R_{1}$ values were 0.0516 $(I>2 \sigma(I))$. The final $w R\left(F^{2}\right)$ values were 0.1530 $(I>2 \sigma(I))$. The final $R_{1}$ values were 0.0655 (all data). The final $w R\left(F^{2}\right)$ values were 0.1681 (all data). The goodness of fit on $F^{2}$ was 1.014. Crystallographic data for 1 reported in this paper have been deposited at the Cambridge Crystallographic Data Centre, under reference number CCDC 1486886.

\subsection{Inhibition of Nitric Oxide Production Assay}

The inhibitory effects of the test compounds on NO production were evaluated based on a detection model with LPS-activated murine macrophage RAW264.7 cells, which was performed as described previously [15]. The concentration of NO in the cultured medium was measured indirectly by analysis of nitrite levels using the Griess reaction. MG-132 was used as a positive control.

\subsection{Cytotoxicity Assay}

The isolates were tested in vitro for their cytotoxicities to inhibit proliferation of five human tumour cell lines, HL60, SMMC-7721, A-549, MCF-7, and SW480. Cell viability was assessed by conducting colorimetric measurements of the amount of insoluble formazan formed in mitochondrion of living cells according to the MTT method [16]. In brief, each cancer cell line was exposed to the compounds dissolved in DMSO at five different concentrations in triplicate for $48 \mathrm{~h}$, with cis-platin as a positive control.

Acknowledgements This work was financially supported by the NSFC-Joint Foundation of Yunnan Province (No. U1502223), the National Natural Science Foundation of China (No. 21402212), the Science and Technology Program of Yunnan province (No. 2015FB173), and the CAS "Light of West China" Program and Youth Innovation Promotion Association CAS (X.-D. Wu).

\section{Compliance with Ethical Standards}

Conflict of interest The authors declare no conflict of interest.

Open Access This article is distributed under the terms of the Creative Commons Attribution 4.0 International License (http:// creativecommons.org/licenses/by/4.0/), which permits unrestricted use, distribution, and reproduction in any medium, provided you give appropriate credit to the original author(s) and the source, provide a link to the Creative Commons license, and indicate if changes were made.

\section{References}

1. C.J. Huang, Flora of China, vol. 43 (Science Press, Beijing, 1997), pp. 65-66

2. Q.Z. Wang, J.Y. Liang, Acta Pharm. Sinica 39, 605-608 (2004)

3. G.Y. Zuo, H.P. He, B.G. Wang, X. Hong, X.J. Hao, Acta Bot. Yunnanica 25, 103-106 (2003)

4. Q.Z. Wang, J.Y. Liang, X. Feng, Chin. Chem. Lett. 21, 596-599 (2010)

5. J. Teng, X.W. Yang, Heterocycles 68, 1691-1698 (2006)

6. N. Shoji, A. Umeyama, A. Iuchi, N. Saito, S. Arihara, K. Nomoto, Y. Ohizumi, J. Nat. Prod. 52, 1160-1162 (1989)

7. G.Y. Zuo, X.S. Yang, X.J. Hao, Chin. Chem. Lett. 11, 127-128 (2000)

8. Y.H. Li, J. He, Y. Li, X.D. Wu, L.Y. Peng, R.N. Du, X. Cheng, Q.S. Zhao, R.T. Li, Helv. Chim. Acta 97, 1481-1486 (2014)

9. M. Bubenyák, M. Pálfi, M. Takács, S. Béni, E. Szökő, B. Noszál, J. Kökösi, Tetrahedron Lett. 49, 4937-4940 (2008)

10. M.J. Frisch, G.W. Trucks, H.B. Schlegel et al., Gaussian 03, revision D.01 (Gaussian Inc, Wallingford, 2005)

11. H. Shigemori, T. Kagata, J. Kobayashi, Heterocycles 59, 275-281 (2003)

12. I.J. Pachter, R.J. Mohrbacher, D.E. Zacharias, J. Am. Chem. Soc. 83, 635-642 (1961)

13. Z.J. Zhang, J. Yang, J. He, X.D. Wu, L.D. Shao, Y. Li, S.X. Huang, R.T. Li, Q.S. Zhao, Tetrahedron Lett. 55, 6490-6494 (2014) 
14. C.Y. Gan, W.T. Robinson, T. Etoh, M. Hayashi, K. Komiyama, T.S. Kam, Org. Lett. 11, 3962-3965 (2009)

15. G.J. Huang, C.H. Pan, F.C. Liu, T.S. Wu, C.H. Wu, Food Chem. Toxicol. 50, 1485-1493 (2012)
16. Y.H. Li, H.M. Li, Y. Li, J. He, X. Deng, L.Y. Peng, L.H. Gao, Q.S. Zhao, R.T. Li, X.D. Wu, Tetrahedron 70, 8893-8899 (2014) 